\title{
Referral request for S. Claus
}

To: $\quad$ Dr. Yull Tyde

From: Y. Ingrid Goh*

Please examine Mr. Claus for the following illnesses during his next physical examination. Please ensure he understands that these work-related risks affect his health. It is highly recommended that Mr. Claus consider an alternative mode of transportation and adapt a healthier lifestyle.

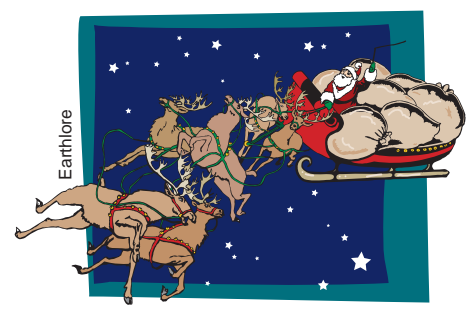

Caisson disease

\section{Meniere's disease}

Respiratory problems

Obsessive-compulsive disorder

Heartburn

Obesity

Hyperglycemia

Hypertension and dyslipidemia

Thermal burns

Frostbite and hypothermia

Cervid diseases
Mr. Claus has only 24 hours to deliver Christmas presents; therefore, he must travel at a minimum speed of 6.25 million km/h in order to cover the Earth's land surface area of about 150 million km². Given this speed and the need to fluctuate between high and low altitudes in an unpressurized vehicle, his body has little time to adjust to the changes in air pressure.

The constant ringing that Mr. Claus hears may not be Christmas sleigh bells. This symptom may be a secondary manifestation of caisson disease.

Mr. Claus has descended many chimneys over many years. The constant acute exposure to soot and ash would certainly predispose him to respiratory problems, including asthma, emphysema and chronic obstructive pulmonary disease.

Mr. Claus is constantly preoccupied with making lists of children's names and checking them twice.

Given the rapid pace of travel and the expectation placed on Mr. Claus to eat the milk and cookies left for him at every stop, indigestion is unavoidable. Please remind him to chew his food thoroughly.

Mr. Claus' polyphagia inevitably contributes to his plumpness. A well-balanced diet and daily exercise routine is highly recommended.

The large amount of sugar found in the immense quantity of milk and cookies he eats may predispose him to diabetes. Secondary complications to diabetes would include heart, kidney and nerve problems. Please have him ask children to leave him healthier snacks.

Once again, Mr. Claus' erratic and unhealthy eating habits predispose him to these conditions. Diet modification is highly recommended.

Mr. Claus may suffer burns owing to absent-minded people who forget to extinguish their fireplace. Perhaps this is why he is often described as having a rosy complexion. Please ask him to consider an alternative route of entrance.

Travelling at high speeds in an open vehicle leaves Mr. Claus susceptible to very cold temperatures. This may account for his waxy complexion.

Please bring to Mr. Claus' attention that his reindeer may be at risk for malignant caterlal fever and chronic wasting disease. In addition, please ensure that his herd of reindeer has been vaccinated against rabies virus.

*A concerned but grateful gift recipient in Toronto, Ont. 